\title{
Knowledge, Attitude and Self-Medication Practice on Antibiotic use amongst General Public in AlorSetar, Kedah, Malaysia
}

\author{
Teh Jing Ying ${ }^{1}$, Zainol Akbar Zainal ${ }^{1 \star}$, Izyan A Wahab ${ }^{1}$, Fauziah Zamri ${ }^{1}$ and Hasniza Zaman Huri ${ }^{2}$ \\ ${ }^{\prime}$ Faculty of Pharmacy, Cyberjaya University College of Medical Sciences, Cyberjaya, Selangor, Malaysia \\ ${ }^{2}$ Department of Pharmacy, Faculty of Medicine, University of Malaya, Kuala Lumpur, Malaysia
}

\section{Article Info}

\section{*Corresponding author:}

Zainol Akbar Zainal

Associate Professor

Cyberjaya University College of Medical

Sciences

63000 Cyberjaya, Selangor Darul Ehsan

Malaysia

Tel: +603 - 83137064

E-mail: zainol.akbar@cybermed.edu.my

Received: January 29, 2018

Accepted: March 13, 2018

Published: March 19, 2018

Citation: Ying TJ, Zainal ZA, Wahab IA, Zamri F, Huri HZ. Knowledge, Attitude and Self-Medication practice on Antibiotic use amongst General Public in AlorSetar, Kedah, Malaysia. Madridge J Pharm Res. 2018; 2(1): 40-46

doi: 10.18689/mjpr-1000107

Copyright: $\odot 2018$ The Author(s). This work is licensed under a Creative Commons Attribution 4.0 International License, which permits unrestricted use, distribution, and reproduction in any medium, provided the original work is properly cited.

Published by Madridge Publishers

\begin{abstract}
Antibiotic use and its linked to antibiotic resistance has become a great public concern. Antibiotic-resistant infections resulted from abuse of antibiotics have causedsubstantial morbidity and mortality worldwide. This problem is so serious that it threatens the achievements of modern medicines. Poor knowledge and attitude amonggeneral public has served as a barrier to appropriate antibiotics utilisation. This study aimed to determine public's knowledge, attitude towards antibiotic use and pattern of self-medication with antibiotic's (SMA) practice in AlorSetar, Kedah. This study also aimed to determine the correlation between knowledge and attitude as well as to study the level of knowledge and attitude among different demographic background. A guided self-administered questionnaire was used in this study. The questionnaire composed of 4 parts; demographic data, knowledge about antibiotic, attitude towards antibiotics use and SMA practice. This cross-sectional study in AlorSetar, Kedah, included 394 respondents sampled via convenient sampling method. The proportions of male and female respondents in this study were $47.2 \%$ and $52.8 \%$ respectively. More than half of the respondents were of Malay ethnic background (59.4\%). Half of the respondents were found to practice SMA and it was found that major source of antibiotics supply intended for SMA was generally obtained from communitypharmacies. This study showedthat the respondents had an overall poor knowledge towards antibiotics (mean score $=42.22 \pm 20.48$ ). The level of knowledge among different education level, monthly income and healthcare related work were statistically significant $(p<0.001)$. Respondents also have poor to moderate attitude towards antibiotics use (mean score $=61.44 \pm 14.02$ ). There was a notable difference in the attitude score between different education level, employment status, monthly income and healthcare related work $(p<0.001)$. Moreover, a positive correlation was also observed between knowledge on antibiotics and attitude towards antibiotic use $(r=0.532, p<0.001)$. This study concluded that overall public in AlorSetar was prevalent in SMA practice. Generally, public in AlorSetar had poor knowledge and moderate attitude towards antibiotics use. Further similar study can be done by involving relatively a larger population to provide a better picture of knowledge and attitude of Malaysian public towards antibiotics use.
\end{abstract}

Keywords: Attitude; Self-medication; Antibiotics. 


\section{Introduction}

Antibiotics and similar drugs, together termed as antimicrobial agents, have been utilized over 70 years to treat infectious diseases. Since the 1940s, antimicrobial agents have notably reduced morbidity and mortality from infectious diseases. However, the rapid emergence of antibiotic resistance has constituted a major health problem globally [1]. Previous study has demonstrated that there was an association between antibiotic resistance and 2-fold increased morbidity and mortality [2].

According to the Malaysian Statistics on Medicine (MSOM) 2009 and 2010, antibiotics remain the major prescribed anti-infective agents by both public and private health-care sectors with 15.4895 defined daily dose (DDD)/1,000 population/day in year 2010 [3]. Antibiotics are the most commonly prescribed drugs, but are often misused and potentially may contribute to antimicrobial resistance [4].

In the United States, 262.5 million courses of antibiotics are prescribed in the outpatient setting corresponding to more than 5 prescriptions written each year for every 6 people [5]. A study done by Ab Rahman et al. [6] reported a high level of antibiotic prescribing among Malaysian primary healthcare clinics in which at least 1 of 5 encounters derived from prescription of an antibiotic. In Malaysia, antibiotic prescribing in private clinics is contributed to $87.0 \%$ of the total antibiotics prescribed in primary health care system.

Antibiotic can lose its ability to effectively control or kill bacterial growth. This situation occurs when bacteria have slowly adapted to the antibiotic, a situation known as antibiotic resistance. In 2011, the WHO has set the theme for World Health Day as 'Combat Antimicrobial Resistance: No Action Today, No Cure Tomorrow'. This indicates a serious global antibiotic abuse crisis which needs to be addressed promptly [7]. The escalation of antibiotic resistance progressively posed a substantial threat to global public health. If this issue left unattended, antibiotic resistance could cast the world back into the dark ages of medicines in which invasive surgeries were impossible and people routinely die from simple bacterial infections. Thus, it is crucial to develop new strategies to minimize antibiotic resistance.

Antimicrobial Resistance Global Report on Surveillance 2014 reported that common bacteria (for example, Escherichia coli, Staphylococcus aureus and Klebsiellapneumonia) are recognized for their remarkable resistance multinational. Such condition can lead to common healthcare associated and community-acquired infections [4]. While in healthcare setting, the concurrence of high antibiotic consumption, critically ill patients and a rising influx of pathogenic species have consistently nurture the growth of resistance [8]. Thus, great attention to infection control practice remains of paramount importance in preventing the propagation of multidrug resistance in hospitals worldwide.

Self-medication is the selection and use of medicines by individuals to treat self-recognised illnesses or symptoms without consulting a medical doctor [4]. Self-medication practice has been reported as being on the rise internationally [9]. Patients who practice SMA are often unaware of the potential consequences such as development of antimicrobial resistance, adverse effects, or aggravation the symptoms $[10,11]$. Additionally, self-medicating individuals do not obtain pertinent information regarding medications' side effects and dosing instructions [12,13]. These situations are believed to arise from patients often obtain medication advice from incompetent personnel, family and friends [14]. In these cases, self-medication may lead to antibiotic overuse, poor adherence to regimens and irrational use of antibiotic.

Generally, SMA practice has linked to several risks for the self-medicated patient [15]. SMA constitute a major form of irrational use of medicines and can cause important risks such as antibiotic resistance, treatment failures, drug toxicity, increase in treatment cost, prolonged duration of hospitalization and increase in morbidity $[16,17]$.

Substantial global evidence has proven that the general community has responsibility in the increase and spread of antibiotic resistance. The WHO urged member countries to initiate educational interventions for patients and the general population aimed at rationalizing the use of antibiotic to combat resistance. Thus, enhancing the public knowledge and improving their attitude towards antibiotic use will be a crucial early plan to maintain antibiotic effectiveness [7]. Understanding public knowledge and attitude towards antibiotic usage will aid for planning and establishing strategies for local health education purposes, and intervention tools to change the practices of clinicians, patients and the public.

\section{Materials and Methods}

\section{Study Design}

A cross-sectional survey was conducted from August to September 2016 in AlorSetar, Kedah. A total 394 respondents were sampled via convenient sampling using a validated guided self-administered questionnaire. The questionnaire used in this study was adopted from previous studies $[18,19]$. The questionnaire was originally developed in English, which was then translated into Malay language. This is because Malay language is the national language of Malaysia and majority of Malaysians could read, speak and write in Malay language.

The study tools were pre-tested (pilot test) on 20 respondents in public areas before the actual research was conducted to ensure that the tools were reliable, appropriate and capable to generate intended results. The validity and reliability of the questionnaire were evaluated in a pilot study. Minor modifications have been made from the pilot test responds to improve the questionnaire presentation, clarity and congruency of meaning. The questionnaire consisted of 4 main sections assessing the demographic data of respondents, knowledge, attitude and self-medication practices toward antibiotic amongst general public. 
Knowledge of respondents on antibiotic was assessed by 14 questions. Areas assessed pertained to the role of antibiotics, identification of antibiotics, dangers of antibiotics, and completion of treatment course. Respondents were requested to choose among 3 options provided which are 'Yes', 'No' or 'Not Sure'. The antibiotic knowledge score was calculated as a continuous variable by summing the respondent's number of correct responses to 14 statements. Every correct answer was coded as 1 score and uncertain or wrong answer was coded as 0 score [19]. The accumulated knowledge score was converted into percentage and categorized into 3 levels indicated by poor $(<50 \%)$, moderate $(50 \%-70 \%)$ and good (>70\%) [20].

The section that assessed respondents' attitude toward antibiotic use was consisted of 8 statements. Respondents will rate the statements on a 5-point Likert scale where 0 means "Not Sure", 1 means "Strongly Disagree", 2 means "Disagree", 3 means "Agree" and 4 means "Strongly Agree". Reverse scoring was used for the negative attitude statement (statement 1 to 6 ). The total score will sum up, with a maximum obtainable score of 32 for each respondent [21]. The total attitude score was converted into percentage and categorized into 3 levels indicated by poor attitude $(<60 \%)$, moderate attitude (60\%-80\%) and good attitude (> 80\%) [22].

Meanwhile, SMA practice among respondents was assessed by 6 questions: 1 filter question, 1 close-ended question and 4 multiple choice questions. A filter question such as "Have you ever treated yourself with antibiotic without consulting physician?" was included in this section in order to determine if the respondents are qualified or experienced enough to answer the subsequent questions. Those who answered "yes" to this question were defined as they practice self-medication and required to continue answering the more specific questions about SMA.

\section{Statistical Analysis}

The data collected from respondents was analysed by using Statistical Package for Social Sciences (SPSS) version 20 for Windows. The level of significance was set as $p<0.05$. Throughout data analyses, normality of continuous data was determined. It was run on score of knowledge and attitude (continuous data) to determine whether parametric or non-parametric test was to be used for the study analysis with demographic data. Continuous data was expressed as mean and standard deviation (parametric test). Categorical data was expressed as frequency and percentage. Continuous data with normal distribution was analysed by using independent t-test, one-way ANOVA or Pearson's correlation test accordingly.

\section{Results}

A total 394 respondents participated in this study (Table 1). Of these, half of the respondents were females. The respondent's age ranged was from 18 to 77 years old with the mean age of $34.65 \pm 13.58$. Most of them were $18-30$ years old and the lowest proportion age group was those respondents aged more than 61 years old. Malay respondents accounted for $\sim 60.0 \%$ of all respondents. This was followed by Chinese with $38.1 \%$, and Indian and other races made for $<3 \%$ of the respondents. With regard to their education level, most of them had only completed secondary school, while minority had a lower education level. More than $70.0 \%$ of respondents had a job. One-third of respondents with monthly income of RM 1,000 to RM 2,000 participated in this study. On the other hand, there were about $10.0 \%$ of respondents' occupations or study was related to healthcare had involved in this study.

A total of 197 respondents were reported utilize antibiotic without consulting medical doctor in the last 12 months. This equates to an overall $50.0 \%$ of the respondents practiced SMA. The main reason for the SMA practice by our participants was most of them (46.8\%) regarded their diseases were simple and not necessitate seeing a doctor. Additionally, there was wide variety of illnesses that have been treated by SMA. However, fever was the most common condition among all the diseases which contributes to a total $40.0 \%$. Surprisingly, in this study, community pharmacies were found to be the dominant source in supply of antibiotics which were used for self-medication (65.0\%).

This study showed the knowledge of respondents towards antibiotic was poor (42.22 \pm 20.48$)$. A statistically significant difference was observed between level of knowledge and demographic data of respondents in term of highest education level, monthly household income and healthcare related work (Table 2).

For the attitude, the study populations have poor to moderateattitude towards antibiotic use (61.44 \pm 14.02). Besides, there was a difference in the attitude score between different education level, employment status, monthly income and healthcare related work $(p<0.001)$. Among all variables, this study showed that the knowledge on antibiotic and attitude towards antibiotic use positively correlated with each other (Table 3).

Table 1. Demographic data of respondents $(n=394)$

\begin{tabular}{|l|l|l|}
\hline Characteristic & \multicolumn{2}{|l|}{ Frequency, $\%$} \\
\hline \multirow{2}{*}{ Gender } & Male & $186,47.2$ \\
& Female & $208,52.8$ \\
\hline \multirow{5}{*}{ Ethnicity } & Malay & $234,59.4$ \\
& Chinese & $150,38.1$ \\
& Indian & $7,1.8$ \\
& Others & $3,0.8$ \\
\hline \multirow{5}{*}{ Ege } & $18-30$ & $210,53.3$ \\
& $31-40$ & $57,14.5$ \\
& $41-50$ & 60.15 .2 \\
& $51-60$ & $51,12.9$ \\
& $\geq 61$ & $16,4.1$ \\
\hline \multirow{3}{*}{ Employmention Level } & Primary School & $38,9.7$ \\
& Secondary School & $188,47.7$ \\
& College/University & $168,42.6$ \\
\hline \multirow{2}{*}{ Healthcare related work } & Employed & $301,76.4$ \\
& Unemployed & $43,10.9$ \\
& Student & $50,12.7$ \\
\hline \multirow{5}{*}{ Monthly Income } & None & $87,22.1$ \\
& No RM1000 & $63,16.0$ \\
& RM 1000 - RM 2000 & $130,33.0$ \\
& RM 2001 - RM 4000 & $84,21.3$ \\
& $>$ RM 4000 & $30,7.6$ \\
\hline
\end{tabular}


Table 2. Difference in knowledge scores between different demographic data of the respondents $(n=394)$

\begin{tabular}{|l|l|l|}
\hline \multirow{2}{*}{ Demographic } & \multicolumn{2}{|l|}{ Score of Knowledge (\%) } \\
\cline { 2 - 3 } & $($ Mean \pm SD) & p value \\
\hline $\begin{array}{l}\text { Gender } \\
\text { Male }\end{array}$ & $41.74 \pm 19.26$ & \\
Female & $42.65 \pm 21.56$ & $0.661_{\mathrm{a}}$ \\
\hline $\begin{array}{l}\text { Ethnicity } \\
\text { Malay }\end{array}$ & $41.33 \pm 20.34$ & $0.297_{\mathrm{a}}$ \\
Non - Malay & $43.53 \pm 20.69$ & \\
\hline $\begin{array}{l}\text { Age (in years) } \\
\leq 30\end{array}$ & $42.61 \pm 21.68$ & \\
$>30$ & $41.77 \pm 19.08$ & $0.682_{\mathrm{a}}$ \\
\hline $\begin{array}{l}\text { Highest Education Level } \\
\text { Primary School or lower } \\
\text { Secondary School }\end{array}$ & $28.20 \pm 14.66$ & \\
College/University & $38.15 \pm 17.36$ & $<0.001_{\mathrm{b}}{ }^{*}$ \\
\hline $\begin{array}{l}\text { Employment Status } \\
\text { Employed } \\
\text { Unemployed }\end{array}$ & $49.96 \pm 21.88$ & \\
\hline $\begin{array}{l}\text { Healthcare-related work } \\
\text { Yes }\end{array}$ & $42.34 \pm 20.82$ & $0.845_{\mathrm{a}}$ \\
No & $41.86 \pm 19.44$ & \\
\hline $\begin{array}{l}\text { Monthly Income } \\
<\text { RM 2,000 }\end{array}$ & $66.99 \pm 25.94$ & $<0.001_{\mathrm{a}}^{*}$ \\
RM 2,001 - RM 4,000 & $39.66 \pm 18.02$ & \\
$>$ RM 4,000 & $38.16 \pm 19.06$ & $<0.001_{\mathrm{b}}{ }^{*}$ \\
\hline
\end{tabular}

Independent t-test (2-tailed) ${ }_{b}$ One-way ANOVA $p<0.05$ for level of significance

Table 3. Difference in attitude scores between different demographic data of the respondents $(n=394)$

\begin{tabular}{|l|l|l|}
\hline Demographic & Scores of Attitude (\%) & \\
\hline & $($ Mean \pm SD) & p value \\
\hline $\begin{array}{l}\text { Gender } \\
\text { Female }\end{array}$ & $61.49 \pm 15.80$ & $0.949_{\mathrm{a}}$ \\
\hline $\begin{array}{l}\text { Ethnicity } \\
\text { Malay }\end{array}$ & $61.38 \pm 16.24$ & \\
Non - Malay & $60.92 \pm 15.81$ & $0.443_{\mathrm{a}}$ \\
\hline $\begin{array}{l}\text { Age (in years) } \\
\leq 30\end{array}$ & $62.18 \pm 16.34$ & \\
$>30$ & $61.49 \pm 15.91$ & $0.946_{\mathrm{a}}$ \\
\hline $\begin{array}{l}\text { Highest Education Level } \\
\text { Primary School or lower } \\
\text { Secondary School } \\
\text { College/University }\end{array}$ & $61.38 \pm 16.18$ & \\
\hline $\begin{array}{l}\text { Employment Status } \\
\text { Employed }\end{array}$ & $49.18 \pm 20.49$ & $<0.001_{\mathrm{b}}{ }^{*}$ \\
Unemployed & $61.05 \pm 13.76$ & \\
\hline $\begin{array}{l}\text { Healthcare-related work } \\
\text { Yes } \\
\text { No }\end{array}$ & $64.64 \pm 19.53$ & $0.004_{\mathrm{a}}{ }^{*}$ \\
\hline $\begin{array}{l}\text { Monthly Income } \\
<\text { RM 2000 }\end{array}$ & $62.72 \pm 15.28$ & \\
RM 2001 - RM 4000 \\
$>$ RM 4000 & $57.29 \pm 17.65$ & \\
\hline
\end{tabular}

Independent t-test (2-tailed) ${ }_{\mathrm{b}}$ One-way ANOVA

$\mathrm{p}<0.05$ for level of significance

\section{Discussion}

SMA results in this study show consistency with a study conducted in Pakistan, which hasconfirmed high rates of SMA practice around $51.0 \%$ [23]. In spite of that, percentage of respondents practice SMA in this study is much higher as compared to other developed countries of the world [24]. The main reason of SMA was similar to a finding by Kumar et al. [25] in which most of the respondents refuse to consult doctor because the disease is mild. The findings of our study supports the statement that in developing countries, antibiotics are viewed as wonder drugs capable of treating a wide variety of illnesses ranging from pain to gastrointestinal problems [26]. The disease conditions requiring respondents to practice SMA is finding was consistent with the previous study done in Nepal [27]. Meanwhile, community pharmaciesremain as the dominant source of supply of antibiotic for SMA might due to profit oriented nature of service delivery in this sector and inadequate supervision [28].

Poor knowledge on antibiotic in this study was supported by a study done in Lithuania, which concluded that public had poor knowledge on antibiotic. However, majority of them were familiar with adverse drug reactions (ADRs) caused by antibiotic [29]. Another study conducted by Desai et al. [30] have shown that most of the public were unaware about the possible detrimental health consequences of antibiotic resistance.

Females were shown to have a relatively higher knowledge towards antibiotic as compared to males. Different finding was showed by a previous study in Shah Alam, Malaysia, where the study reported that there was a difference statistically between different genders where females were much more knowledgeable about antibiotic than males [31]. Inconsistent finding in both studies may due to difference in geographical areas and different degrees of exposure to healthcare information.

Result in this study showed that there was no difference between the levels of knowledge with age of respondent. In contrast, study in Oman showed that there was a difference between age group and the level of knowledge [32]. Meanwhile, study conducted by Tenaiji et al. [33] was able to demonstrate that level of knowledge increase with age, owing to they have greater lifetime experience with illnesses and medication management [34].

Level of knowledge did not differ among ethnicity of respondents. Evidence showed that antibiotic knowledge and perceptions can be affected by ethnicity and culture [35]. A local study done by Oh et al. [19] also showed knowledge on antibiotic were highest among Chinese, followed by Indian and Malay. However, since the ethnicity distribution is not equally distributed thus it cannot exactly represent the knowledge level among different races on antibiotic.

Education level among respondents in this study has shown to have important factor that influenced the level of knowledge. Better knowledge on antibiotic was associated with higher education level. The results were consistent with previous studies on the association between antibiotic knowledge and education level [36]. Higher education was associated with accurate knowledge of antibiotic [37]. This could be due to respondents with higher education able to understand the educational messages.

Apart from that, respondents who were employed showed higher knowledge than unemployed respondents. Study showed unemployed parents had a lower likelihood of getting a good score in all the outcomes considered, if 
compared with employed parents. Inconsistency in the results may have resulted from different target populations.

Meanwhile, the differences between level of knowledge and monthly household income were statistically significant, which explained knowledge on antibiotic somewhat affected by monthly household income. There was a similar study found that the knowledge on antibiotic were associated with the income [38]. Due to lack of knowledge, general public with lower income was not aware of dangers associated with antibiotic misuse [10].

Results from this study shows that respondents who work or study in a healthcare related field were found to be more knowledgeable than those who did not work or study in a healthcare related field. This finding was parallel with a study done in Kuwait which found an association between level of knowledge and healthcare related work or study [21]. According to Huang et al. [39], healthcare personnel represent a highly educated group of medical team, their knowledge in relation to antibiotic can greatly impact on antibiotic-related issues in the future.

Most of respondents had poor to moderate attitude towards antibiotic use in this study, which showed lacking of good attitude among respondents. In contrast, study done by Abubakar et al. [40] reported overall Nigerian postgraduates students show positive attitude towards medications use. This study found that, more than half of the respondents expect medical doctor to prescribed antibiotic when they suffered from common cold. In parallel with another study done by Shehadeh et al. [41] in Jordan, most of the respondents demand for antibiotic prescription from physicians to treat common cold symptoms. In this aspect, public's attitude greatly influenced the prescribing pattern of doctors. Hence, medical doctors prescribing pattern could contribute a major impact on antibiotic usage. According to Zyoud et al. [42], good public attitude toward antibiotic is an important factor in rational antibiotic use and therefore minimizing development of antibiotic resistance. Thus, healthcare professional play a crucial role to extensively counsel their patients in order to raise the awareness in importance of a correct antibiotic consumptions [43].

Gender has been found to be one of the most important factors influencing health-related behaviours [44]. Attitude on antibiotic use among males were shown to be better than females but it was not statistically significant. Parallel finding was demonstrated by a study that assessed public knowledge and attitude towards antibiotic usage in Penang, Malaysia. Consistency finding in both of these studies might due to similar respondents baseline characteristics as both involved more female than male and those with age 18 years old and above. Previous study found that women were more frequently to have poor attitude towards medication than men and is reasonable to assume that poor attitude towards medication associated with poor adherence [44].

In this study, respondents aged 30 and below were shown to have better attitude towards antibiotic use. A study conducted by Siddharth et al. [45] also reported that attitude scores vary across different age groups. A study in Saudi Arab also found that younger age was associated with poor attitude on medication [46]. This situation could lead to the improper utilization of medications which in turn may lead to serious repercussions. Moreover, attitude towards medicines duringyoung age may affect the appropriate use of medications later in adulthood.

There was no difference in the level of attitude between ethnic groups. In contrast to a study done in Putrajaya, Malaysia showed that there were differences between attitude and ethnicity and it was statistically significant [47]. Inconsistency in this findings may due to the target populations were not the same in which the study done by K.K \& C.C [47] was conducted among populations that attended local hospital. According to Grigoryan et al. [48], ethnic and cultural are one of the factor that can affects levels of public attitude concerning antibiotic use and awareness of antibiotic resistance.

Education plays a remarkable role in changing one's attitude on abuse of prescription drug [49]. Furthermore, educated respondents were more likely to seek preventive and curative care and concern on the health-related issues that could possibly give harm or disadvantages to their health. Among all the others, respondents that have higher education level were likely to have more positive attitude. This is parallel with the study done in Kuwait which had discovered that respondents with higher education found to express more positive attitude towards antibiotic use [21].

Employment status can influence attitude towards antibiotic use. This finding was further supported by a previous study that concerned with knowledge and attitude on antibiotic among public [47]. The study had concluded that there were differences between attitude and different employment status. The consistent in findings may due to sufficiently similar respondent background characteristic as both studies were conducted in Peninsular Malaysia.

Income is the key determinant to access to healthcare. Result from this study shows among all the different income group, respondents who have monthly income more than RM 4,000 have better attitude on antibiotic use and the differences were statistically significant. Similar finding was found in a study conducted in Thailand which the attitude toward antibiotic use have a strong association with monthly income [50]. Increase in wealth promotes utilisation of healthcare services provided by government. Poverty caused limited access to healthcare resources and thus those with low household income showed poor attitude on to antibiotic use [51].

Healthcare providers can play an important role in controlling antibiotic resistance, such as improving patients' attitude towards antibiotic use. Those respondents who work or study in healthcare related field have better attitude. This result contradicts with a study done in a Southern India teaching hospital, whereby the medical students which are the future healthcare provider were found to have casual attitude towards antibiotic use. Study found that $50 \%$ of antibiotic prescription by medical doctors is potentially inappropriate [43]. 
Meanwhile, this study shows that the knowledge on antibiotic and attitude towards antibiotic use positively correlated with each other. The findings were similar with few studies which concluded that there was positive correlation between knowledge and attitude towards antibiotic use $[19,47]$. Consistency of the results might due to the same target population and all the studies were conducted in Peninsular Malaysia. Therefore, in order for public to have good attitude towards antibiotic use, they must be adequately educated on knowledge of antibiotic.

\section{Conclusion}

This study found that SMA practice among respondents was prevalent. The SMA rates were considered high in this study as compared to other countries. The main reason of SMA practice was due to the public perceived their conditions as simple illness. Generally, this study demonstrated poor knowledge and moderate attitude towards antibiotic use among study population. In addition, the higher level of knowledge, the better attitude towards antibiotic use among respondents. Hence, it is essential to reinforce the importance of public knowledge on antibiotic.

\section{Acknowledgement}

I would like to express my deepest appreciation to my supervisor, Assoc. Prof. Dr. Zainol Akbar Zainal for his guidance and support throughout this period. Besides, I would also like to thank my co-supervisor, Dr. Izyan A. Wahab for her ongoing support and advice to improve my study. I would also like to thank my family members that always are there for me. Last but not least, I would like to extend my heartiest appreciation to all participants in this study and also CUCMS for giving me this precious research opportunity.

\section{References}

1. Ventola $\mathrm{CL}$. The antibiotic resistance crisis: part 1: causes and threats. $P T$. 2015; 40(4): 277-283.

2. Eliopoulos GM, Cosgrove SE, Carmeli $\mathrm{Y}$. The impact of antimicrobial resistance on health and economic outcomes. Clin Infect Dis. 2003; 36(11): 1433-1437. doi: $10.1086 / 375081$

3. Fauziah AS, Kamarudin A, Aklima NONN. Malaysian statistics on medicines 2009 \& 2010. Ministry of Health Malaysia. 2014; 1-206.

4. WHO. Antimicrobial resistance. 2014.

5. Hicks LA, Bartoces MG, Roberts RM, et al. US outpatient antibiotic prescribing variation according to geography, patient population, and provider specialty in 2011. Clin Infect Dis. 2015; 60(9): 1308-1316. doi: 10.1093/cid/civ076

6. Ab Rahman N, Teng CL, Sivasampu S. Antibiotic prescribing in public and private practice: a cross-sectional study in primary care clinics in Malaysia. BMC Infect Dis. 2016; 16: 208. doi: 10.1186/s12879-016-1530-2

7. WHO. World Health Day. 2011.

8. Roca I, Akova $M$, Baquero $F$, et al. The global threat of antimicrobial resistance: Science for intervention. New Microbes New Infect. 2015; 6: 2229. doi: 10.1016/j.nmni.2015.02.007

9. Verma RK, Mohan L, Pandey M. Evaluation of self-medication among professional students in North India: proper statutory drug control must be implemented. Asian J Pharm Clin Res. 2010; 3(1): 60-64.
10. Barah F, Gonçalves V. Antibiotic use and knowledge in the community in Kalamoon, Syrian Arab Republic: a cross-sectional study. East Mediterr Health J. 2010; 16(5): 516-521.

11. Stosic R, Dunagan F, Palmer H, Fowler T, Adams I. Responsible self-medication: perceived risks and benefits of over-the-counter analgesic use. Int J Pharm Pract. 2011; 19(4): 236-245. doi: 10.1111/j.2042-7174.2011.00097.x

12. Balbuena $F R$, ArandaAB, Figueras $A$. Self-Medication in Older Urban Mexicans. Drugs Aging. 2009; 26(1): 51-60. doi: 10.2165/0002512200926010-00004

13. Albarrán KF, Zapata LV. Analysis and quantification of self-medication patterns of customers in community pharmacies in southern Chile. Pharm World Sci. 2008; 30(6): 863-868. doi: 10.1007/s11096-008-9241-4

14. Ramay BM, Lambour $P$, Cerón A. Comparing antibiotic self-medication in two socio-economic groups in Guatemala City: a descriptive crosssectional study. BMC Pharmacol Toxicol. 2015; 16: 11. doi: 10.1186/ s40360-015-0011-3

15. Hughes $C M, M c$ Elnay JC, Fleming GF. Benefits and Risks of Self Medication. Drug Saf. 2012; 24(14): 1027-1037.

16. Donkor ES, Tetteh-Quarcoo PB, Nartey P, Agyeman IO. Self-medication practices with antibiotics among tertiary level students in Accra, Ghana: A cross-sectional study. Int J Environ Res Public Health. 2012; 9(10): 35193529. doi: 10.3390/ijerph9103519

17. Goossens $H$, Ferech $M$, Stichele RV, Elseviers M. Outpatient antibiotic use in Europe and assaciation with resistance: a cross-national database study. The Lancet. 2005; 365(9459): 579-587. doi: 10.1016/S01406736(05)17907-0

18. Ahmad A, Khan MU, Srikanth $A B$, et al. Evaluation of Knowledge, Attitude and Practice about Self-medication among Rural and Urban North Indian Population. International Journal of Pharmaceutical and Clinical Research. 2015; 7(5): 326-332.

19. Oh AL, Hassali MA, Al-Haddad MS, Sulaiman SAS, Shafie AA, Awaisu A Public knowledge and attitude towards antibiotic usage: A cross-sectional study among the general public in the state of Penang, Malaysia. $J$ Infect Dev Ctries. 2011; 5(5): 338-347. doi: 10.3855/jidc.1502

20. Chandrakanth P, Mohamed Saleem TS, Madhan Mohan Reddy, Gopinath C, Madhan Mohan Rao. Assessment of Public Knowledge and Attitude Regarding Antibiotic Use in A Tertiary Care Hospital. Asian J Pharm Clin Res. 2016; 9(1): 118-122.

21. Awad Al, Aboud EA. Knowledge, attitude and practice towards antibiotic use among the public in Kuwait. PLoS One. 2015; 10(2): e0117910. doi: 10.1371/journal.pone.0117910

22. Lv B, Zhou Z, Xu G, et al. Knowledge, attitudes and practices concerning self-medication with antibiotics among university students in western China. Trop Med Int Health. 2014; 19(7):769-79.

23. Zafar SN, Syed R, Waqar $S$, et al. Self-medication amongst university students of Karachi: prevalence, knowledge and attitudes. J Pak Med Assoc. 2008; 58(4): 214-217.

24. Bilal $M$, Haseeb A, Khan MH, et al. Self-medication with antibiotics among people dwelling in rural areas of Sindh. J Clin Diagn Res. 2016; 10(5): OC08-OC13. doi: 10.7860/JCDR/2016/18294.7730

25. Kumar $V$, Mangal $A$, Yadav $G$, Raut $D$, Singh S. Prevalence and pattern of self-medication practices in an urban area of Delhi, India. Medical Journal of DY Patil Vidyapeeth. 2015; 8(1): 16-20. doi: 10.4103/0975-2870.148828

26. Biswas M, Roy MN, Manik MIN, et al. Self medicated antibiotics in Bangladesh: a cross-sectional health survey conducted in the Rajshah City. BMC Public Health. 2014; 14(1): 847. doi: 10.1186/1471-2458-14-847

27. Pant N, Sagtani RA, Pradhan $M$, et al. Self-medication with antibiotics among dental students of Kathmandu - prevalence and practice. Nepal Med Coll J. 2015;17:47-53.

28. Ocan $M$, Obuku EA, Bwanga $F$, et al. Household antimicrobial selfmedication: a systematic review and meta-analysis of the burden, risk factors and outcomes in developing countries. BMC Public Health. 2015; 15: 742. doi: 10.1186/s12889-015-2109-3 
29. Pavydè E, Veikutis V, Mačiulienè A, Mačiulis V, Petrikonis K, Stankevičius E. Public knowledge, beliefs and behavior on antibiotic use and selfmedication in Lithuania. Int J Environ Res Public Health. 2015; 12(6): 70027016. doi: 10.3390/ijerph120607002

30. Desai AJ, Gayathri GV, Mehta DS. Public's Perception, Knowledge, Attitude and Behaviour on Antibiotic Resistance - A survey in Davangere City, India. Journal of Preventive Medicine and Holistic Health. 2016; 2(1): 17-23.

31. Qamar M, Abdullah NS, Khan J, Mahmud A, Ahmad A. Knowledge and Attitude Towards Antibiotic Usage Among General Public in Shah Alam, Malaysia. UK Journal of Pharmaceutical and Biosciences. 2014; 2(6): 60-66. doi: 10.20510/ukjpb/2/i6/91175

32. Jose J, Jimmy B, Alsabahi AG, Al Sabei A. A Study Assessing Public Knowledge, Belief and Behavior of Antibiotic Use in an Omani Population. Oman Med J. 2013; 28(5): 324-330. doi: 10.5001/omj.2013.95

33. Tenaiji A, Al Redha K, Khatri F, et al. Knowledge, Attitudes and BehaviorTowards Antibiotic Use Among Parents in Al-Ain City, United Arab Emirates. Int J Infect Dis. 2008; 12(1). doi: 10.1016/j.jijid.2008.05.1271

34. Gonzales R, Lopez-Caudana AE, Gonzalez-Flores T, Jayanthan J, Corbett KK, Reyes-Morales $\mathrm{H}$. Antibiotic knowledge and self-care for acute respiratory tract infections in Mexico. Salud Publica Mex. 2012; 54(2): 152-157.

35. Alden DL, Tice A, Berthiaume JT. Antibiotics and upper respiratory infections: The impact of Asian and Pacific island ethnicity on knowledge, perceived need, and use. Ethn Dis. 2006; 16(1): 268-274.

36. Vallin M, Polyzoi M, Marrone G, Rosales-Klintz S, Wisell KT, Lundborg CS. Knowledge and attitude towards antibiotic use and resistance - A latent class analysis of a Swedish population-based sample. PLoS One. 2016; 11(4): 1-18. doi: 10.1371/journal.pone.0152160

37. André M, Vernby A, Berg J, Lundborg CS. A survey of public knowledge and awareness related to antibiotic use and resistance in Sweden. J Antimicrob Chemother. 2010; 65(6): 1292-1296. doi: 10.1093/jac/dkq104

38. Abu Taha A, Abu-Zaydeh AH, Ardah RA, et al. Public Knowledge and Attitude Regarding the Use of Antibiotics and Resistance: Findings from a Cross-Sectional Study Among Palestinian Adults. Zoonoses Public Health. 2016; 63(6): 449-457. doi: 10.1111/zph.12249

39. Huang $Y, G u$ J, Zhang $M$, et al. Knowledge, attitude and practice of antibiotics: a questionnaire study among 2500 Chinese students. BMC Med Educ. 2013; 13: 163. doi: 10.1186/1472-6920-13-163

40. Abubakar AR, Simbak NB, Haque M. Knowledge, attitude and practice on medication use and safety among Nigerian postgraduate-students of UniSZA, Malaysia. International Journal of Pharmaceutical Research. 2014. 6(4): 104-110.
41. Shehadeh M, Suaifan G, Darwish RM, Wazaify M, Zaru L, Alja'fari S Knowledge, attitude and behavior regarding antibiotics use and misuse among adults in the community of Jordan. A pilot study. Saudi Pharm J. 2012; 20(2): 125-133. doi: 10.1016/j.jsps.2011.11.005

42. Zyoud $\mathrm{SH}$, Taha $\mathrm{AA}$, Araj KF, et al. Parental knowledge, attitude and practices regarding antibiotic use for acute upper respiratory tract infections in children: a cross-sectional study in Palestine. BMC Pediatr. 2015; 15: 176. doi: 10.1186/s12887-015-0494-5

43. Gualano MR, Gili R, Scaioli G, Bert F, Siliquini R. General population's knowledge and attitude about antibiotics: A systematic review and metaanalysis. Pharmacoepidemiol Drug Saf. 2015; 24(1): 2-10. doi: 10.1002/ pds.3716

44. Thunander Sundbom L, Bingefors K. Women and men report different behaviours in, and reasons for medication non-adherence. Pharm Pract (Granada). 2012; 10(4): 207-221.

45. Tevatia S, Chaudhry S, Rath R, Dodwad V. A Questionnaire Based Survey on Knowledge, Attitude and Practice of Antibiotics Among Dental and Paramedical Students- a Cross Sectional Survey. World J Pharm Pharm Sci. 2016; 5(5): 1205-1216. doi: 10.20959/wjpps20165-6726

46. Eldalo AS, Yousif MA, Abdallah MA. Saudi school students' knowledge, attitude and practice toward medicines. Saudi Pharm J. 2014; 22(3): 213 218. doi: 10.1016/j.jsps.2013.05.007

47. Lim KK, Teh CC. A cross sectional study of public knowledge and attitude towards antibiotics in Putrajaya, Malaysia. Southern Med Rev. 2012; 5(2): 26-33.

48. Grigoryan L, Burgerhof JG, Degener JE, et al. Attitudes, beliefs and knowledge concerning antibiotic use and self-medication: a comparative European study. Pharmacoepidemiol Drug Saf. 2007; 16(11): 1234-43. doi: 10.1002/pds. 1479

49. Nobakht AGM. The Impact of Education on Knowledge and Attitude of Medical Students about the Abuse of Prescription Drugs in Iran. Journal of Medical Practice and Review. 2017; 1(1): 12-16.

50. Sirijoti $K$, Hongsranagon $P$, Havanond $P$, Pannoi W. Assessment on KAP regarding antibiotic use in Thailand. Journal of Health Research. 2014; 28(5): 299-307.

51. Gupta RPS, de Wit ML, McKeown D. The impact of poverty on the current and future health status of children. Paediatr Child Health. 2007; 12(8): 667-672. doi: 10.1093/pch/12.8.667 